\title{
Flashes da cidade
}

Maria Zilda Ferreira Cury I UFMG / CNPq

Resumo: No romance eles eram muitos cavalos, de Luiz Ruffato, apresentamse 60 flashes da cidade de São Paulo, imagens captadas por um narrador, muitas vezes, com um olhar repleto de compaixão. Tal olhar confere um sentido ético às narrativas.

Palavras-chave: Flashes urbanos, Olhar compassivo, Uma ética da narrativa.

(...) a pluralidade bumana é a paradoxal pluralidade de seres singulares

Hannah Arendt

A construção da cidade, atribuída primitivamente a Caim, indicou a sedentarização de povos nômades. Por isso o traçado da cidade - quadrado, símbolo da estabilidade - se opõe à configuração circular dos acampamentos. Na verdade, trata-se de uma estabilidade apenas aparente uma vez que a cidade sempre se apresenta como um espaço em constante mobilidade, em interminável transformação.

Caim, o primeiro homem nascido do homem e da mulher, o primeiro que trabalha a terra, o primeiro a fazer uma oferta que não é aceita por Deus, o primeiro assassino - é o que revela a face da morte - é também o primeiro errante

1. Cf. Chevalier; GHeERBrant, 1991, p. 238. 
e, principalmente, o primeiro que constrói a cidade. Marcado com o sinal da maldição divina, é, simultaneamente, símbolo da responsabilidade do homem. A condição humana afirma-se na cidade, à qual o homem almeja e tem direito.

Com raízes no solo urbano, no contexto atual do país cuja feição predominantemente rural foi substituída pela vida agitada e violenta que caracteriza suas grandes metrópoles, as produções culturais contemporâneas insistem na encenação do espaço urbano: uma cidade desgastada, cujo tecido social encontrase rompido, metáfora da impossibilidade de reconstituição identitária positiva do país. "A urbanização do imaginário da literatura brasileira é um fenômeno recente, porém irreversível". ${ }^{2}$

Em artigo enfocando o cinema brasileiro, publicado na Folha de S. Paulo em 2004, intitulado "Dialética da Marginalidade: caracterização da cultura brasileira contemporânea”, João Cezar de Castro Rocha, desde o título, explicitamente dialoga com o conhecido ensaio de Antonio Candido "Dialética da Malandragem: caracterização das Memórias de um Sargento de Milícias". ${ }^{4}$ O conceito de malandragem desenvolvido por Candido, segundo o ensaísta, não serviria mais como chave para a leitura da nossa produção cultural, uma vez que ficou defasado, suplantado pela violência que atinge o corpo social brasileiro. Como nos lembra Castro Rocha, citando Candido, o malandro aguarda, no fundo, "ser finalmente absorvido pelo pólo convencionalmente positivo", expectativa já descartada pelo marginal. Referese também Castro Rocha à teoria desenvolvida por Roberto da Matta (1997) segundo a qual, na sociedade brasileira, o mundo cotidiano, o mundo das festas e o mundo oficial articulariam um mosaico peculiar, no qual a fratura é recoberta por aparente unidade. Como resposta ao conflito e à violência inerentes à sociedade brasileira, a política do favor, o jeitinho, a malandragem garantiriam a aparência de harmonia. Sob a roupagem da "cordialidade", da "ginga", da esperteza - marcas características da produção cultural brasileira - violência e exclusão continuariam a efetivamente presidir as relações sociais no Brasil. Hoje, com a violência guindada a personagem principal de romances e filmes tais como Cidade de Deus ou Amarelo Manga, de letras de música e programas de TV, a dialética da marginalidade forneceria base conceitual mais apropriada para levantar o véu dessa aparente harmonia,

2. PINTO, 2004, p. 83. O ensaio foi primeiramente publicado na Revista do Instituto de Estudos Brasileiros (Universidade de São Paulo), n. 8, de 1970.

3. ROCHA, 2004 .

4. CANDIDO, 1993. 
deixando a nu a perversa realidade de exclusão e desigualdade em que continuam a viver amplos setores da população de nossos grandes centros urbanos. Novas categorias de análise são, pois, exigidas para a leitura do nosso contexto cultural, marcado, hoje, por tão grande violência, praticamente autônoma e se autoalimentando, e para a qual o conceito carnavalizante, que indicaria a "incorporação da desordem ao mundo da ordem”, não mais parece servir.

A hipótese da emergência da dialética da marginalidade ajuda a compreender o ponto comum de um grande número de produções recentes que desenham uma nova imagem do país; imagem essa definida pela violência, transformada em protagonista de romances, textos confessionais, letras de música, filmes de sucesso, programas populares e mesmo séries de televisão.

A reflexão é interessante para o levantamento de algumas características de linha ficcional da série literária brasileira contemporânea.

Representações da pobreza e da marginalidade, do mundo das drogas e da prostituição, personagens migrantes, o universo dos marginais e dos excluídos do sistema dão a tônica a tais produções. Expressam, contudo, tais produções, diferenças que se configuram no espaço simbólico, com variações nas suas estratégias narrativas, nas vozes enunciativas que privilegiam, embora sob o denominador comum da temática da violência.

São textos que até chegam, muitas vezes, a constituir um gênero literário novo, modulado numa narrativa formalmente marcada pela concisão e rapidez, como registros ininterruptos de realidades em movimento célere e que não têm repouso, que se deixam apreender na sua precária momentaneidade. Uma forma breve, brevíssima na verdade, o chamado miniconto. A série literária brasileira, atualmente, até com grande originalidade se pensarmos na produção contemporânea em geral, apresenta muitos textos com essa forma narrativa:

Seu efeito de recepção é muito forte exatamente por sua condensação. O discurso direto, tão freqüente no conto, é muitas vezes dispensado, em nome de um ritmo de narração quase alucinante. Isso o transforma numa metáfora da velocidade com que circulam os seres, as mensagens, os objetos, os textos nas sociedades contemporâneas. ${ }^{6}$

5. ROCHA, 2004, p. 6.

6. WALTY et al, 2001, p. 138. 
Tais conceitos são apropriados para a leitura do livro (pequenas crônicas? cenas rápidas? romance? minicontos?) Eles eram muitos cavalos, de Luiz Ruffato. São setenta narrativas, flashes da cidade de São Paulo ("O Neon vaga veloz por sobre o asfalto irregular (...) negra nesga na noite negra", q7ue passam como fachos de neon diante do leitor - "são paulo relâmpagos (são paulo é o lá fora? é o aqui dentro?)" (p. 94) - desconcertando-o, instaurando um efeito de desconforto e estranhamento. O título e a epígrafe usados pelo escritor servirão de balizas para a leitura que pretendo, com umas poucas incursões "incidentais" em produções de outros criadores contemporâneos, chamados para dialogar com o texto que aqui se privilegia. Intenta-se mostrar que, na já referida disputa simbólica deste espaço de representação, o narrador dos textos de Ruffato se distingue por um olhar ético sobre os personagens que transitam nos relatos.

O título do conjunto de textos foi tirado ao penúltimo bloco de versos romance LXXXIV ou Dos cavalos da Inconfidência de O Romanceiro da Inconfidência, de Cecília Meireles.

O gênero utilizado pela poeta tem origem medieval. Mas, a partir do século XVII, o termo romance já designava narrativas breves, muitas delas pertencentes à memória popular. Fiel a formas de oralidade - já que o Romanceiro da Inconfidência bebeu nas fontes anônimas da tradição - Cecilia Meireles subverteu o relato histórico da Inconfidência Mineira, desconstruindo-o pela via da valorização de vozes marginais, de lendas e crendices, recriando a matéria histórica pelo aproveitamento de enunciações variadas. Veja-se que o título do livro de Ruffato, que de saída soa estranho ao leitor, dialoga com o gênero adotado no Romanceiro, como parte da estrutura prismática que enforma as narrativas rápidas do escritor mineiro. Eles eram muitos cavalos,/ mas ninguém mais sabe os seus nomes,/sua pelagem, sua origem... é como Cecília descreve os obscuros cavalos que percorreram Vila Rica nos tempos terríveis da Inconfidência. Também as anônimas criaturas que atravessam São Paulo (mas a cidade é o de dentro ou o de fora?), apresentadas com a técnica da parataxe, integram a multidão, a massa impulsionada por buscas angustiosas ("aquela mulher que se arrasta espantalha por ruavenidas do morumbi", p. 70), quase todos sem nome, misturados aditiva e indistintamente a animais, aos restos da cidade ("mendigos bêbados acobertam-se em caixas de

7. RUfFATO, 2005 , p. 11 . Todas as citações do texto de Luiz Ruffato foram tiradas desta e edição e serão, doravante, referidas no corpo do texto apenas pelo número da página.

8. MEIRELES, 1975 , p. 262. 
papelão, cachorros magros arrombam sacos de lixo, motoristas de táxi jogam porrinha num ponto improvisado, uma mulher oferece incenso indiano, o bebê dormitando sob a barraca, carros passam, o metrô fechado, ônibus vazios, um carro da polícia sirene disparada (...)", p. 126).

Uma cidade atravessada por seres anônimos, vulneráveis, submetidos à opressão e que desaparecem sem deixar rastros e com os quais ninguém se importa, sujeitos dispersos, movimentando-se num espaço público retraído, simultaneamente reprodutores da violência e suas maiores vítimas. ("depois jogaram ele no camburão e sumiram por essa são paulo tão comprida encheram ele de porrada torturaram", p. 102).

Embora trabalhando com outros propósitos, Frederic Jameson nos fala da representação literária do anonimato, da despersonalização, não como perda da identidade pessoal, mas sim sua proliferação.

O termo anonimato não significa aqui, portanto, a perda da identidade pessoal, do nome próprio, e sim sua multiplicação: não mais a média sociológica ou exemplo sem rosto ou o mínimo denominador comum, mas sim a associação de um indivíduo com uma pluralidade de outros nomes e indivíduos concretos.

Assim, o "anonimato" recobriria um conceito tanto sociológico como cultural, voltado para o quotidiano tomado como espaço onde se encontram os anseios, modestos embora, do dia-a-dia, lado a lado das forças onipresentes que os frustram, impedindo a realização de anseios e necessidades. A distância entre o anseio e a realidade é denunciada no texto de Ruffato tanto na ostentação dos poucos que podem muito ("Na esquina com a Rua Estados Unidos, o tráfego da Avenida Rebouças estancou de vez. Henrique afrouxou a gravata, aumentou o volume do toca-cedê, Betty Carter ocupou todas as frinchas do Honda Civic estalando de novo, janelas cerradas, cidadela irresgatável, lá fora o mundo, calor, poluição, tensão, corre-corre. Meninos esfarrapados, imundos, escorrem água nos pára-brisas dos carros, limpam-nos com um pequeno rodo, estendem as mãozinhas esmoleres, giletes escondidas entre os dedos...", p. 81) como na "publicidade" que estimula o consumo de todos, sem distinguir os muitos que podem muito pouco ("Ah! O da pedra vermelha no anular, Hum..., o que lembra um ésse, Lindo, princesa!, devolve, Ah! não vai levar? (...) Ui! Desvencilha-se, a tentação pespegante, as pernas, segregadas

9. JAMESON, 1994, p. 108. 
na calça-uniforme azul-escuro (...) Ah! um alguém sério, crente, um lar, filhos, afastado de onde barra-pesada mora, casas tristes barracos, mortos (...) no Shopping Light, sem perguntar o preço, madame, baixar as caixas de sapato, madame (...), p. 48-49).

Tal representação, nos diz Jameson, embora peculiar à experiência literária e cultural do Terceiro Mundo, também é apreensível nas multidões sem rosto do Primeiro Mundo. ("Arrumado, em três anos de Nova York, o apê, superlegal; o salário de chapeiro, imagine!, de chapeiro!, digno. p.120). A literatura contemporânea mundial, diga-se de passagem, também se ocupa desses "nãocidadãos", guindados a protagonistas de narrativas que não mais dão lugar a grandes heróis, seres à margem do Estado de bem-estar social dos países desenvolvidos,.

(...) parece-me que é aqui - no ocaso do antigo sujeito psíquico, no retorno à tradição da narrativa oral e a uma literatura de anseios e vida diária e na experimentação da história 'anonimamente', antes que sob a égide de grandes homens, grandes nomes, 'heróis' históricos mundiais é aqui onde as interseções, bem como as diferenças mais radicais entre culturas pós-modernas do Primeiro Mundo e as culturas dos inúmeros Terceiros Mundos podem ser exploradas de maneira mais frutífera. ${ }^{10}$

Os setenta minicontos de Ruffato formam, em móbile, conjuntos provisórios, cujos fragmentos se articulam a outros, em novas configurações, compondo paisagens assustadoras ("os ônibus os caminhões os carros as luzes São Paulo Televisão...”, p. 15), onde se movimentam os personagens da cidade. Captados por câmera que filma em vertigem, são eles refrações de sujeitos solitários ("instaleime num quarto, você se lembra?,sexta-feira à noite, Hotel Amazonas, Avenida Vieira de Carvalho, lá embaixo, barulho um restaurante italiano, outro, comida rápida árabe, carros, ônibus, lá embaixo, nas ruas transversais, eu sabia das prostitutas, dos meninos fumando crack, dos assaltantezinhos pé-de-chinelo, eu sabia da noite, e deitei, mas não era alívio que sentia, nem remorso, era não sei o quê, saudade, talvez, (...)”, p. 127), sem valor ou interesse, seres à margem: o rapaz que comete pequenas infrações para garantir o presente do dia das mães, o operário que se espatifa na calçada em frente ao restaurante de luxo, a jovem vendedora assaltada e assassinada diante do leitor, o cachorro sarnento, a suja e faminta menina de rua ("Tá relampiano, cadê neném/Tá vendendo drops no sinal pra alguém”"), a senhora

10. JAMESON, 1994, p. 112.

11. "Relampiano" de Lenine. 
idosa em longa viagem de ônibus para encontrar o filho, o velho contínuo a que ninguém dá atenção, o índio bêbado e idiotizado. (Ai, são pais-de-santo, paus-dearara são passistas. São flagelados, são pingentes, balconistas. Palhaços, marcianos, canibais, lírios, pirados ${ }^{12}$ ). Eles eram muitos, mas ninguém mais sabe sua origem ou identifica seu pelame, igualados na sua exclusão, mas forçando sua presença repetida para o leitor.

Como por acaso, de esguelha, a câmera flagra instantâneos das classes média e alta: políticos corruptos, empresários, intelectuais a que o olhar do narrador - satírico, às vezes até perverso - não poupa: o professor que lê Vigiar e Punir, de Michel Foucault, alheio à infelicidade da mulher, num texto cujo título ("O que quer uma mulher"), ironicamente, recupera a pergunta do texto de Freud; pai e filho num Mercedes, a caminho do McDonald's; o médico - "pés vestidos de finas meias brancas" - de plantão, vendo televisão (mas, afinal, São Paulo é exibida aqui dentro dentro ou lá fora? "Gostava de assim permanecer, olhos semicerrados adivinhando, o bombardeio das cores, o dia passado a limpo na parede amarelada do cubículo", p. 109) e que se recusa a salvar a vida do homem que assaltara sua casa; os casais burgueses combinando trocas de experiências. Rapidamente se passa para páginas de jornal: classificados de encontros amorosos, ofertas de empregos, oração de Santo Expedito.

Mas não há acaso nas escolhas discursivas de Ruffato. A forma procuradamente fragmentária do conjunto, elege a ruína como estratégia discursiva que reenvia as narrativas à representação do também arruinado corpo social, busca formal de grande rendimento expressivo. Como nos diz Susini-Anastopoulos, a fragmentação e a ruína são temas essenciais da estética contemporânea, e mais ainda, elementos reveladores da situação ontológica do homem moderno. ${ }^{13}$

No presente caso, o conjunto de estratégias investindo no fragmento, na precariedade, adensa a esfera da reflexão, paradoxalmente universalizando-a: os seres errantes da cidade de São Paulo formam painel da condição humana, alargada no seu desvalimento.

O olhar do narrador igualmente passa por inventários diversos: ofertas de emprego, seções de jornal com propostas de relacionamentos, desestabilizando a leitura, subvertendo a expectativa de leitura mais tradicional do que seja literário. Catálogos, recortes de jornal, corrente de orações, informações meteorológicas.

12. "O rancho da goiabada" de João Bosco e Aldir Blanc.

13. SUSINI-ANASTOPOUlOS, 1997, p. 126-127. 
Metonímias em abismo de uma poética da precariedade que imprime novas funções a estes "restos" de linguagens, deslocadas como papéis jogados nas ruas da cidade. Listas de livros de uma estante (best-sellers? cultura de massas? auto-ajuda?), cardápio literário rápido (Uma estante, p. 51-52) a que se segue, quase ao final do livro, cardápio de bufê finíssimo (Cardápio, p. 146), ambos afixados sem qualquer comentário. Que leitor, no entanto, deles se serviria sem constrangimento ou culpa, em meio a tantos violentos relatos de exclusão?

Este olhar que nos encara de dentro do texto ("não vai passar nunca esse mal-estar, nunca essa sensação de inutilidade", p. 126) comunga, muitas vezes "vê-com" os personagens, partilhando sua dor, sua "pequenez", sua insignificância, a amargura de seus anseios frustrados, fazendo ressoar as memórias em círculo do corpo passado, doendo no espanto do corpo presente: "de pé a paisagem que murcha a velha rente à janela rosto rugas bolsa de náilon desmaiada no colo dentro coisas enroladas em jornais vestido branco sandália de plástico fustigando o joanete cabelos grisalhos olhos assustados nunca se acostumará ao trânsito à correria ao barulho a corda canta na roldana o balde traz água salobra pouca o silêncio das vacas mugindo a secura crestada entre os dedos do pé (p. 94-95). E o olhar do narrador continua seu trânsito pelo ônibus: a adolescente cujos sonhos se esmigalham, o homem com a marmita, e o ônibus continua sempre seguindo e a cidade passando rápida (são paulo é, afinal, o de dentro ou o de fora?) "as luzes os postes dos carros dos painéis eletrônicos dos ônibus e tudo tem a cor cansada e os corpos mais cansados mais cansados" para, ao final, incorporar-se, ganhar corpo neste trânsito: "a batata das minhas pernas dói minha ${ }^{14}$ cabeça dói e" sem ponto final, apontando nesta sintaxe virtual uma possível conclamação ao leitor para que também ele adentre o veículo. (Mas o narrador é o de dentro ou o de fora?)

Atente-se, então, para uma outra baliza apresentada por Ruffato e que, como já disse, forneceria segunda porta de leitura para seu texto, funcionando como uma espécie de contraponto ao título. Trata-se de trecho do salmo 81, usado como epígrafe: "Até quando julgareis injustamente, sustentando a causa dos ímpios?". No texto bíblico, os juízes, autoridades que representavam Deus junto ao povo, que julgavam e governavam, são chamados ao tribunal divino para prestarem contas de seus atos. "Defendei o oprimido e o órfão, fazei justiça ao humilde e ao pobre. Libertai o oprimido e o indigente, arrancai-o das mãos dos ímpios", exortaos o Senhor para que eticamente não se recusem a "olhar" para os mais fracos .

14. Grifos por mim acrescentados. 
Esta conclamação presente no salmo - voz aparentemente externa ao texto - é filtro para o olhar do narrador (ele o convocado? o intelectual? nós, os leitores?). A aparente dispersa pluralidade de destinos, retratos da condição órfã dos excluídos, ganha seu espaço de enunciação, contraditório embora, mediada pelo olhar pleno de compaixão, de simpatia do narrador.

A cidade que seu olhar vasculha, espaço discursivo em movimento, abre-se para a enunciação, em ruínas, reitere-se, muitas vezes em silêncio, desses pretensos afásicos culturais: não para falar por eles, ou em seu lugar, mas para que se criem espaços para a emergência de suas vozes: a do velho contínuo, a da mulher traída gravada na secretária eletrônica, a voz vicária das correntes de orações.

Eles eram muitos cavalos... Como a humilde donzelinha descrita por Cecília Meireles na sua desvalida pobreza e subtração ("Donzelinha, donzelinha,/ fecha esses olhos sombrios./As montanhas são tão altas!/ Os ribeiros são tão frios!/ O reino de Deus, tão longe/ dos humanos desvarios!", cuja pequenez e desamparo despertam a compaixão do narrador, também a prostituta do conto de Ruffato, vilipendiada, obrigada a satisfazer a luxúria de fregueses drogados, sonha com um tratamento que a distinga do anonimato ("tratam a mulher com a maior atenção, e não estão preocupados se é bonita ou feia, gorda ou magra, branca ou preta, querem é cuidar da mulher, porque sabem que mulher precisa disso, de atenção, p. 121), que gere a possibilidade de um outro espaço, de uma outra vida, de reconhecimento de sua radical alteridade. Reino de Deus, na linguagem bíblica, aponta a utopia, que o profeta e o salmista assumem ao denunciar as injustiças, ao marcar a distância entre o existente e o possível.

O olhar "para o rosto do outro", como diz o filósofo Emmanuel Lévinas (1980), dizer um sim ao outro, com "simpatia", palavra de origem grega, ${ }^{16}$ traduzível no latim por "compaixão", com-paixão. ${ }^{17}$ Como nos ensina o dicionário, pela

15. MEIRELES, 1975 , p. 41.

16. "Lat. sympathia, ae 'afinidade, relação, analogia' < gr. sumpátheia,as, donde, ger., 'comunhão de sentimentos ou de impressões', der. de sumpathês,ês,és 'que toma parte nos sentimentos de outrem', donde 'que tem os mesmos sentimentos', de sún 'juntamente' e gr. páthos,eos-ous 'o que se experimenta (aplicado às paixões da alma ou às doenças)'; ver 1sin- e pat(o)-; f.hist. 1600 sympathia, 1632 simpathia." (Dicionário Eletrônico Houaiss da Lingua Portuguesa).

17. "lat. compassìo,ónis 'sofrimento comum, comunidade de sentimentos, opiniões comuns, simpatia" (Dicionário Eletrônico Houaiss da Língua Portuguesa). 
etimologia dos termos chegamos ao significado de comunhão de sentimentos, ao partilhar de sentimentos e do sofrimento de outrem.

Com este narrador entramos, de saída até com indiferença, porta adentro da escolinha de periferia acompanhando a professora. Com ele/com ela vamos fazendo o inventário da destruição gratuita, descabida: "No corredor, onde desaguavam as três salas-de-aula, gizes esmigalhados, rastros de cola colorida, massinhas-de-modelar esmagadas, folhas de papel sulfite estragadas, uma lousa no chão vomitada, trabalhinhos rasgados...” (p. 30). (Natureza morta se intitula o fragmento.) Com ele/ela entramos na hortinha: legumes destruídos, arrancados, pisados. "(...) as crianças caminhando, com cuidado, por entre os pequenos cadáveres verdes, olhos baços," (de quem os olhos?) "e ela, até onde a vista alcança, observa as escandalosas casas de tijolos à mostra, esqueletos de colunas, lajes por acabar, pipas singrando o céu cinza, fedor de esgoto". Sutilmente se desloca o olhar do narrador, mistura-se ao da professora, janela da alma, mediação para a comunhão com o olhar do leitor: "um comichão na pálpebra superior esquerda e a solidão e o desespero" (p. 30).

Olhar o outro, sentir com o outro, sabendo-se não ser o outro. Responsabilizar-se pelo outro. Tudo isso compõe uma ética presente no ato de narrar, uma função ética do ato de narrar. O narrador reuniria estas vozes emudecidas dos desvalidos, embora, reitere-se, sem qualquer pretensão a falar no lugar deles, mas deles se aproximando por esta "qualidade" do olhar, ocupando o lugar paradoxal e simultâneo da proximidade e da distância. Emmanuel Levinas (1980) coloca a distância que separa o sujeito do outro como o espaço para a construção de sua ética, já que o Eu está no mundo com os outros, só definindo-se enquanto ser na medida da relação interpessoal. Dizer sobre o outro já é de alguma forma responder a ele, responsabilizar-se radicalmente por ele, nos diz o filósofo. Sobre isso também nos fala Paul Ricoeur (2000), na medida em que valoriza a experiência "do outro", da vivência antecipada do sujeito com o sofrimento e a morte do outro, como a marca do desejo do ser no mundo, como a experiência que fundamenta e dá um sentido radical - eu diria, radicalmente ético - para a morte e para a vida. Ambas as posturas filosóficas movimentam-se no sentido de deixar o outro falar. O olhar capta o que o outro fala, os sinais que emite.

A esse propósito, gostaria de comentar rapidamente um filme do cineasta tunisiano Abdellatif Kechiche, L'esquive (O esquivo) que, como tantas outras produções artísticas da contemporaneidade, aproxima-se deste espaço criado por Ruffato em seus textos.

O filme conta a história de jovens da periferia parisiense, dos chamados "banlieues sensibles", isto é, daqueles bairros afastados do centro, habitados por 
famílias pobres. Bairros com infra-estrutura deficitária e cuja população, composta sobretudo por imigrantes árabes e africanos, é vista com desconfiança pelos franceses de extração social pretensamente mais legitimada. A ação é centrada num grupo de jovens.

Krimo, quinze anos, o pai na prisão, vive com sua mãe numa das "cités" do bairro, grandes conjuntos habitacionais, sem muita privacidade, típicos da periferia parisiense. Lydia, juntamente com outros colegas, ensaia, na escola, a peça de teatro Le jeu de l'amour et du hasard, de Pierre de Marivaux. ${ }^{18}$ Mesclamse, com finura e sensibilidade, embora com tensão extrema, o quotidiano desses jovens, seus amores desencontrados e as trapalhadas - as "maurivaudages" - dos personagens da peça.

Desde início do filme, instala-se um efeito de estranhamento no espectador: que língua é esta encenada no filme? Soa como algo parecido com francês, mas é uma língua sincopada, que jorra aos borbotões, crivada de palavrões e gírias, misturada a termos árabes afrancesados, num quase dialeto muito próprio dos jovens de periferia: uma língua gritada, rápida, uma necessidade premente de respostas, de escuta. O ouvido custa a se acostumar e este é o primeiro entre muitos níveis de impossibilidade de expressão encenados no filme.

Os jovens - quase afásicos culturais - também têm dificuldades de se fazerem entender entre si e pelos outros, como por exemplo, a policiais que os abordam, violentamente. Krimo se enamora de sua colega Lydia, mas não logra convencê-la a aceitá-lo. Mesmo tomando o lugar do rapaz que contracena com ela na peça de Marivaux, não consegue expressar-se adequadamente, quer pela dificuldade óbvia com o vocabulário e as formas de expressão do século XVIII, quer por não conseguir interpretar o personagem. E aí se cruzam o texto literário e o texto da vida, desequilibrando o espectador, complexificando o pacto de leitura da ação, prismaticamente adensando as interpretações. Essa série de estranhamentos perturba o espectador que igualmente se pergunta a qual comunidade se deve reportar como sendo a sua.

O ensaio da peça é supervisonado pela professora, que pontua as intencionalidades do texto de Marivaux, respondendo às dúvidas sobre o modo adequado de interpretação: o rico se traveste de pobre e vice-versa, mas nem um nem outro têm sucesso no seu jogo, que propositadamente não convence ninguém. Conclui a professora, com o dramaturgo, que não nos desembaraçamos de uma

18. Pierre de Chamblain de Marivaux, 1688-1763, escritor francês, teatrólogo. 
linguagem, de um certo tipo ou assunto de conversação, de uma determinada forma de expressão, de determinadas posturas que indicam de onde viemos. $O$ texto insiste em que se é prisioneiro da condição social e este lócus a partir do qual se constrói o discurso deixa suas marcas. Diz a professora que, se há um jogo amoroso, falta o outro elemento - o acaso - do par presente no título da peça. Já que ninguém escapa à sua condição, que sempre deixa um rastro, o acaso não conta. No entanto, há que se pensar em saídas para o constrangimento da fixidez do lugar social, em espaços criativos que podem exercer função subversora.

A literatura e seu ensino são os espaços mediadores para que esses jovens percebam e, de certa forma, superem os limites impostos por seu lugar social. É a possibilidade de se enxergarem a si mesmos e de expressarem sua necessidade de amor, seu direito ao saber e ao prazer estético. Se é a possibilidade de se perceber o mundo como ele é, insiste o filme na assinalação do como ele poderia ser e, registre-se, valendo-se da mediação de um texto da assim chamada literatura canônica, a que todos têm direito e em cuja defesa com sensibilidade ímpar se lança esse filme. Para tanto, faz incidir as lentes de sua câmera sobre a figura da professora: sem nome, mas marcando sua presença em rápidas aparições com a sensibilidade e brilho do olhar. Logra despertar nos jovens o amor pelo texto, fisgados que foram pelos seus jogos de linguagem, pela sua trama amorosa, pela possibilidade de expressão que ele lhes faculta. Enquanto pais, alunos e professores se encontram e conversam no final da apresentação, o que se escuta, como música de fundo, é uma canção árabe evidenciando a inevitabilidade mestiça das culturas, a singularidade de cada um na configuração de sua condição plural. E tudo isso mediado pelo olhar de "com-paixão" da câmera que distingue a todos, aparentemente captando-os no seu indistinto anonimato.

Aqui se constata a urgência da atenção às identidades, do respeito à alteridade, ao anseio, mesmo silencioso ou desarticulado, pela individuação e cidadania por parte daqueles que estão à margem. Assim como o narrador compassivo dos contos de Ruffato. Através de toques sutis cria-se um espaço de ação pela palavra que remete à figura do intelectual/narrador. O velho maltratado pela família na narrativa ironicamente denominada 'A vida antes da morte' recorre ao narrador, vizinho seu que tem livros ("Dias desses, demandou à porta, desajeitado, indagou, a dentadura folgada dentro da boca banguela, se eu tinha algum livro, um que falasse como é a vida depois da morte, os poucos tufos de cabelos brancos cheirando naftalina", p. 70); um eu/narrador claramente marcado ("Em minha direção, a menina, aposto nem quinze anos ainda”, p. 125) namora títulos estrangeiros na 
banca de jornais antes de entrar com a jovem na lanchonete; mas também é o que escreve com a mão alheia, assumindo o estilo mais convencional, e sentimentalmente materno, as mal traçadas linhas, partilhando o sentimento sofrido do outro (Carta, p. 105).

A experiência transmitida (vivida em simpatia, em sún 'juntamente' e gr. páthos,eos-ous 'o que se experimenta ) pelo narrador colocaria em evidência seu papel na cena pública, ao lhe ser atribuída uma função ética através da linguagem, que não hesita em questionar seu fazer (enquanto narrador/intelectual), incluindo também o leitor na sua perplexidade e simpatia diante do sofrimento do outro.

Errância e anonimato: condições do habitante da grande cidade.

Primeira aquisição do homem, seu nome, Caim, indica seu sonho: posse. Posse sonhada da terra e de si mesmo para o que precisa acrescentar o fruto de seu trabalho à terra de Deus e tornar-se o senhor de seus atos e libertarse do mistério da predestinação. Muito mais do que o cultivo da terra, a cidade seria a expressão dos feitos humanos a que está ligada a condenação de errância imposta por Deus a Caim. ${ }^{19}$ Errância que a cidade metaforiza na busca de um futuro a ser indefinidamente construído.

Eles eram muitos cavalos é urgente nomeá-los.

Abstract: The novel eles eram muitos cavalos, by Luiz Ruffato, presents 60 flashes of São Paulo, images captured by a narrator whose gaze is often compassionate. Such gaze gives the narrative an ethical dimension Key words: Urban flashes, A compassionate gaze, A narrative ethics.

19. Cf. CHEVALIER; GHEERBRANT, 1991, p. 162-163. 


\section{Referências Bibliográficas}

ARENDT, Hannah. A condição bumana. Trad. Roberto Raposo. 5. ed. Rio de Janeiro: Forense Universitaria, 1991.

BÍBliA SAGRADA. Trad. da Vulgata e anotada por Pe. Matos Soares. 9. ed. São Paulo: Paulinas, 1955.

CANDIDO, Antonio. Dialética da malandragem. In: O discurso e a cidade. São Paulo: Livraria Duas Cidades, 1993.

CHEVAlier Jean; GHEERBRANT, Alain. Dicionário de símbolos: mitos, sonhos, costumes, gestos, formas, figuras, cores, números. 5. ed. Trad. Vera da Costa e Silva et al. Rio de Janeiro: José Olympio, 1991.

COSTA PINTO, Manuel da. Literatura brasileira hoje. São Paulo: Publifolha, 2004.

Da MATTA. Roberto. Carnavais, malandros e heróis: para uma sociologia do dilema Brasileiro. 6. ed. Rio de Janeiro: Rocco, 1997.

JAMESON, Frederic. Sobre a substituição de importações literárias e culturais no Terceiro Mundo: o caso da obra testemunhal. In: GAZOLLA, Ana Lúcia Almeida (Org. e Trad.). Espaço e imagem: teorias do pós-moderno e outros ensaios. Rio de Janeiro: Editora UFRJ, 1994.

LEVINAS, Emmanuel. Totalidade e infinito. Lisboa: Edições 70, 1980.

MEIRELES, Cecília. Romanceiro da Inconfidência. São Paulo: Círculo do livro, 1975.

MELO, Nelio Vieira de. A ética da alteridade em Emmanuel Levinas. Porto Alegre: EDIPUCRS, 2003.

RICOEUR, Paul. La mémoire, l'histoire, l'oubli. Paris: Éditions du Seuil, 2000.

ROCHA, João Cezar de Castro. Dialética da marginalidade: caracterização da cultura, contemporânea. Folha de S. Paulo. Caderno Mais! 29 de fevereiro de 2004.

RUFFATO, Luiz. Eles eram muitos cavalos. 3. ed. São Paulo: Boitempo, 2005.

SUSIN, Luiz Carlos et al. (Org.). Éticas em diálogo: Levinas e o pensamento contemporâneo: questões e interfaces. Porto Alegre: EDIPUCRS, 2003.

SUSINI-ANASTOPOULOS, Françoise. L'écriture fragmentaire: Définitions et enjeux. Paris: PUF, 1997.

WALTY, Ivete; PAULINO, Graça; FONSECA, Maria Nazareth; CURY, Maria Zilda. Tipos de textos, modos de leitura. Belo Horizonte: Formato, 2001. 